\title{
Spectroscopic Two-dimensional Observation of Flames in an Industrial Furnace for Steel Processing
}

\author{
Kuniyuki KITAGAWA ${ }^{1)}$, Noriyuki KONISHI ${ }^{2)}$, Shinsuke ITOH, Toyohiro TERABAYASHI ${ }^{3)}$, Norio ARAI", \\ Tatsuya SHIMADA ${ }^{4)}$, Toshikazu AKIYAMA, Shinichiro FUKUSHIMA ${ }^{5)}$ and Yasuo OHKUBO ${ }^{6}$
}

\author{
Nagoya University, Furo-cho, Chikusa-ku, Nagoya 464-8603, Japan \\ 1) Research Center for Advanced Energy Conversion \\ 2) Department of Molecular Design and Engineering, Graduate School of Engineering \\ 3) Department of Applied Chemistry, Graduate School of Engineering \\ NKK Corporation, 1-1-2, Marunouchi, Chiyoda-ku, Tokyo 108-0075, Japan \\ 4) Keihin Works \\ 5) Head Office \\ 6) Kokan-Keisoku Corporation
}

In this study, a spectroscopic method is applied to measure two-dimensional (2D) distributions of flame temperatures during regenerative combustion of natural gas with highly preheated air in a test furnace of industrial size. By using a CCD camera fitted with an optical bandpass filter, the $2 \mathrm{D}$ distributions of the continuum emission from soot particles in premix and diffusion flames are measured at two different wavelengths. Subsequently, the temperature is determined on the basis of the two-color $2 \mathrm{D}$ thermometry, in which the ratio of the $2 \mathrm{D}$ emission intensity distributions is converted into the $2 \mathrm{D}$ temperature distribution with much higher spatial resolution in comparison with those obtainable by thermocouples. The emission profiles of NO radiation also were measured and the results are discussed in conjunction with difference in the temperature profiles of the flames.

KEY WORDS: highly preheated air; regenerative burner; natural gas; two-dimensional temperature distribution; CCD camera; industrial size furnace; steel processing; premix and diffusion combustion.

\section{Introduction}

Presently, energy saving is among the most important issues for furnaces used for steel processing as well as other industrial ones. The improvement of the thermal ef ficiency leads to the decrease in the consumption of fossil fuels and consequently the suppression of emission of carbon dioxide causing the green house effect.

For the purpose of increasing the thermal efficiency with low emission of nitrogen oxides(NOx) causing the acid rain problem, a new combustion technique, highly preheated combustion has been studied as the national project, "High Performance Industrial Furnace Development Project" supported by the New Energy Technology Development Organization of Japan (NEDO). As a result, it has been clarified that energy saving up to ca. $30 \%$ is attainable by this technique and that the lower flammability limit and spatial temperature uniformity are drastically improved ${ }^{1-6)}$.

Use of air highly preheated by a regenerator, a heat accumulating heat from the exhaust gas, increases the emission level of NOx. In order to overcome this problem, air with a low oxygen concentration down to several $\%$ is used. Combustion at such a low oxygen concentration is allowed only under a condition of highly preheated air. Furthermore, it was found that the emitted concentration of NOx was significantly different during premix and dif fusion combustion with highly preheated air.

In this study, a test furnace of industrial size with regenerators to attain high thermal efficiency was constructed for natural gas combustion, with the support by the NEDO project. Natural gas is preferable from environmental viewpoint because of lower emission of carbon dioxide than that from oil combustion.

Two-dimensional spectroscopic measurements were made to illustrate the profiles of the flame temperature and spectral intensity of spontaneous emission of radiation from excited NO molecules during premix and diffusion combustion. These measurements were used to unravel the source of the difference in the NOx level in the exhaust gas between the premix and diffusion combustion.

\section{Experimental Procedure}

2.1. Test furnace for regenerative combustion of natural gas

Figures 1 and 2 show the schematic diagrams of the test furnace of industrial size and the detail of the burner, constructed for this study on regenerative combustion of natural gas with highly preheated air, respectively. The furnace has a size of $8 \mathrm{~m}$ in length, $2 \mathrm{~m}$ in width and $2 \mathrm{~m}$ in height and is installed with the two regenerative burners, A and $B$ on its opposite ends. The maximum temperature attainable with natural gas in this furnace is $1,623 \mathrm{~K}$ and the maximum input load is $1,163 \mathrm{~kW}$. The eight water-cooled pipes are located on the furnace floor at the interval of $1 \mathrm{~m}$ (see Fig. 1). These pipes are used for the heat output load. The 52 R-type thermocouples of $1 \mathrm{~mm}$ in diameter are suspended from the furnace ceiling at the grid points of $1 \mathrm{~m}$ interval. The junction points of 22 thermocouples are located on the horizontal plane including the burner axis, and used to measure the temperature profile. 


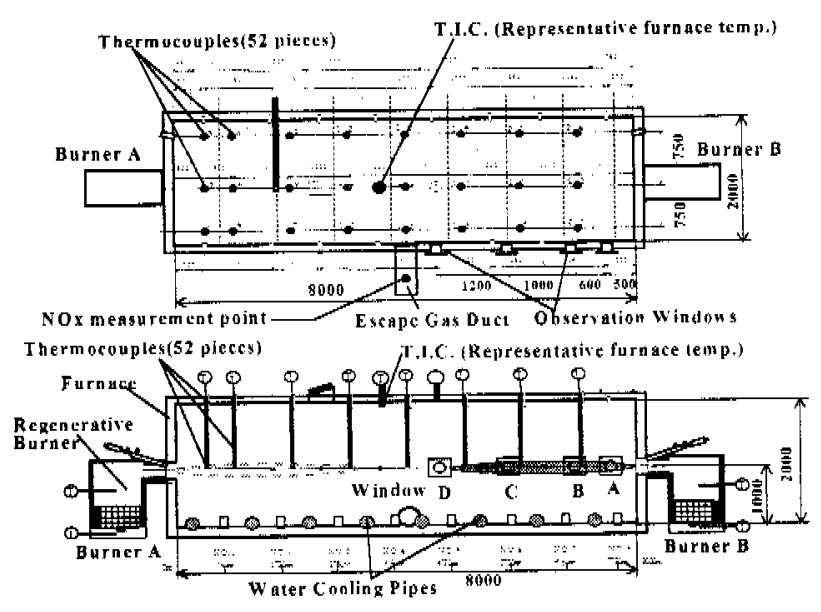

Fig. 1 Schematic of the regenerative test furnace for natural gas.

The pair of the regenerative burners are switched every $30 \mathrm{sec}$. and consequently the combustion flame is formed alternately. The exhaust gas is passed through the honeycomb regenerator of ceramics and the exhaust heat is accumulated here. During the following combustion period, the fresh air is preheated here up to $1,550 \mathrm{~K}$. A part of the exhaust gas is mixed with the fresh air to lower the oxygen concentration down to $2 \%$. The maximum natural gas fed by the burner is $100 \mathrm{Nm}^{3} / \mathrm{h}$ and the maximum linear velocity of the injected air is $100 \mathrm{~m} / \mathrm{s}$.

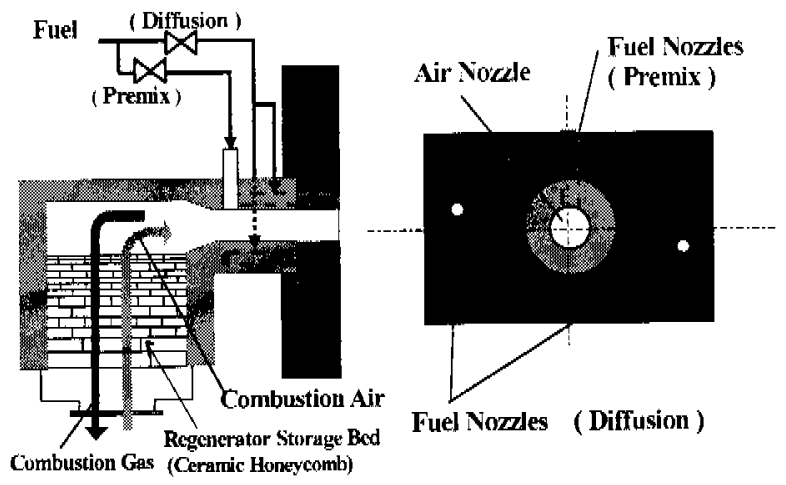

Fig. 2 Detail of the regenerativc burner.

The two types of combustion, premix and diffusion are tested for a study on the differences in the NOx emission and the spatial distribution of flame temperature (see Fig. 2). In case of the premix combustion, the fuel, natural gas is mixed with the highly preheated air in the central injector pipe on the flame axis. For the diffusion combustion, on the other hand, the fuel is injected from the two off-axis nozzles separated from the air injection nozzle (see Fig. 2).

The test furnace is installed with 4 windows, A, B, C and $D$ with a quartz plate of $15 \mathrm{~cm}$ in diameter, for spectroscopic observation. In order to prevent the optical system from overheating by radiation from the flame, the windows have an iron screen coated with alumina/silica wool. Except for the measurement time, the windows are closed with these screens.

\subsection{Fuel and operating conditions}

The fuel used for the test furnace was natural gas composed of $88.8 \mathrm{v} / \mathrm{v} \%$ of methane, $5.2 \mathrm{v} / \mathrm{v} \%$ of ethane, 3.0 $\mathrm{v} / \mathrm{v} \%$ of propane, $2.9 \mathrm{v} / \mathrm{v} \%$ of butane and $0.1 \mathrm{v} / \mathrm{v} \%$ of nitrogen.

The following operating conditions of the test furnace were used for both premix and diffusion combustion: a combustion load input of $771 \mathrm{~kW}$, a preheated air temperature of $1,403 \mathrm{~K}$, an equivalence ratio of 0.878 , an oxygen concentration of $2.6 \%$, a linear air velocity of 63 $\mathrm{m} / \mathrm{s}$, the Reynolds number of air at the injection nozzle of 39,600 and the resulting representative furnace temperature of 1,533 K(measured by the thermocouple, T.I.C in Fig.1).

\subsection{NOx concentration}

The NOx concentration was measured with a chemiluminescence NOx meter (Shimadzu NOA7000) by continuously sampling the exhaust gas from the ventilation duct located at the middle point of the furnace (see Fig. 1).

\subsection{Spectroscopic two-dimensional measurements}

Figure 3 shows schematic diagram of the optical system for spectroscopic two-dimensional measurements. This system consists of a focusing lens of synthetic quartz ( $f=80$ $\mathrm{mm}$ and $50 \mathrm{~mm}$ in diameter), and a CCD camera of $250 \times 120$ pixels (Santa Barbara Instrument, Model SBIF ST6UV) fitted with an optical bandpass filter and neutral density (ND) filters in series. The system is mounted on a laboratory-made optical bench and accommodated in a cover. Air cooled at ca. $15^{\circ} \mathrm{C}$ was flowed inside the cover to prevent the $C \mathrm{CD}$ camera from overheating. Figure 4 demonstrates the photographs of the optical system placed in front of an observation window of the test furnace.

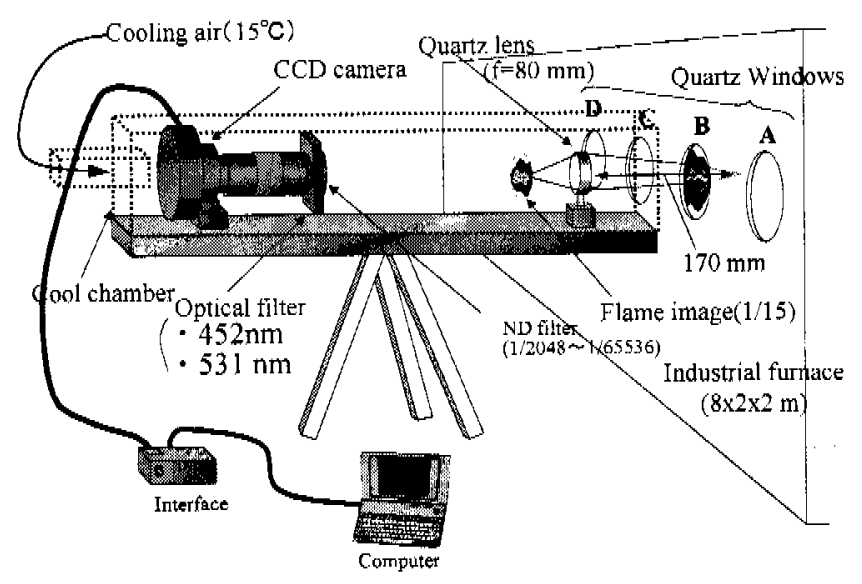

Fig. 3 Schematic of the optical measurement system.

The flame image is focused with a magnification ratio of $1 / 15$ by the lens and taken at a selected wavelength by the filter-attached CCD camera. Thus, a monochromatic image is obtainable and it gives two-dimensional information on specified chemical species and flame temperature after processed by a microcomputer.

Two-dimensional distribution of spontaneous emission of radiation from NO species in the flame also was measured by attaching an interference filter of $231 \mathrm{~nm}$ in the central wavelength and $22 \mathrm{~nm}$ in bandpass width to the CCD camera. No ND filter was used since the spectral 
intensity of $\mathrm{NO}$ emission was weak. The exposure time was 10 sec.
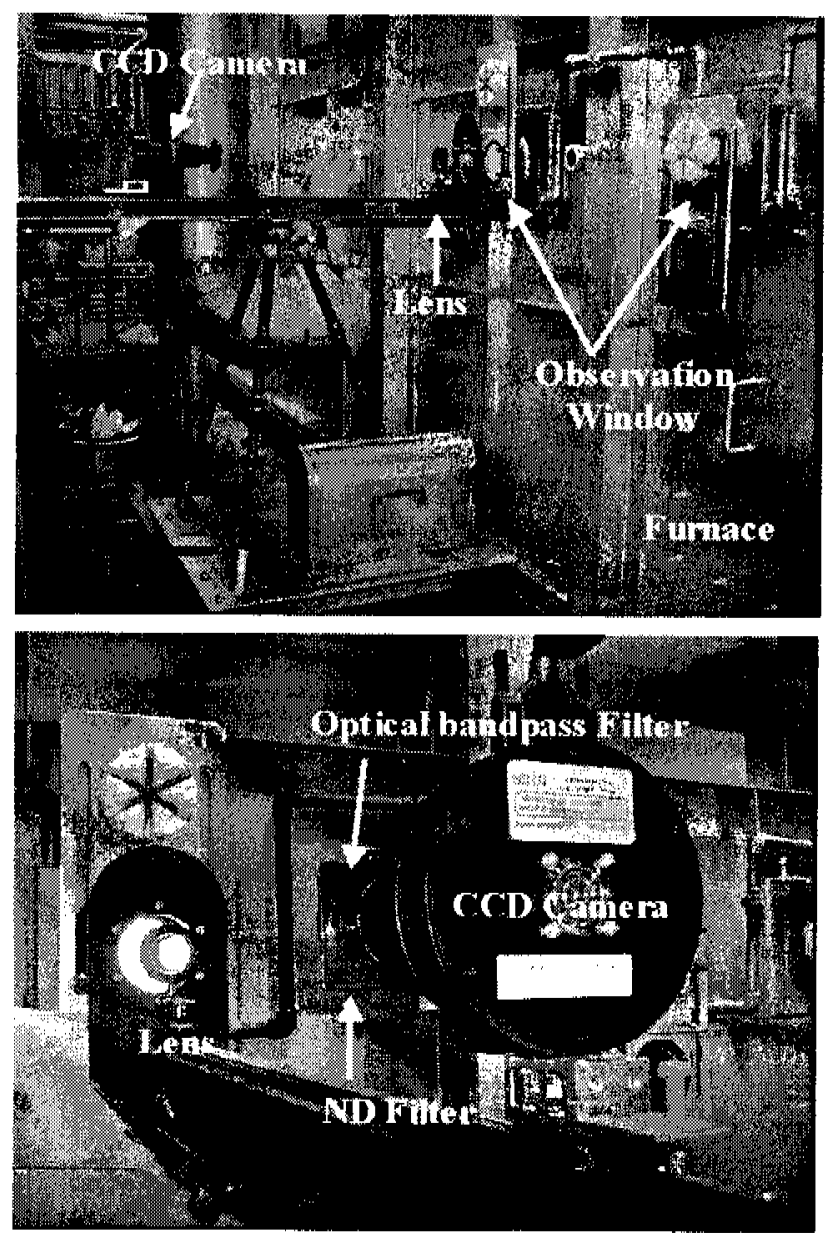

Fig. 4 Photographs of the furnace and optical measurement system

Two-dimensional two-color thermometry based on the Planck's law was applied to measure two-dimensional distributions of flame temperatures. The spectral intensities of the continuum radiation from soot particles in a luminous flame were two-dimensionally measured at two dif ferent wavelengths of $452( \pm 8)$ and $531( \pm 9) \mathrm{nm}$, respectively. The ratio is calibrated against the thermocouple temperature at the close position as that measured by the CCD camera. The two-dimensional ratios at the pixels were converted into two-dimensional temperature distribution. The errors due to the temperature dependence of the emissivity on the soot particles is supposed to be almost canceled since the narrow bandpass and close wavelengths were used: narrow bandpass two-dimensional thermometry: The flame temperature thus obtained is the soot surface temperature calibrated against the temperature measured with a thermocouple. More strict and detailed discussion on different temperatures will be made elsewhere.

In all the measurement, the background emission intensity of radiation from the furnace wall was measured under the same conditions of the optical system, while the flame was turned off.

A multichannel CCD spectrometer (JASCO, Model MD-25T) was also used to check the absence of line spectra on the continuum spectrum from soot particles, since the narrow bandpass two-dimensional wo-color thermometry has a possibility of more serious errors caused by them.

\section{Results}

3.1. Visual observation in the longitudinal direction

Figure 5 shows the one-shot photographs of the premix and diffusion flames on the burner B, which were viewed near axially and taken by video camera for home use, located in front of an observation window on the wall of the burner A. It is noted that the volume of the diffusion flame is much larger than that of the premix flame: the vertical rods seen together are the thermocouple tubes.

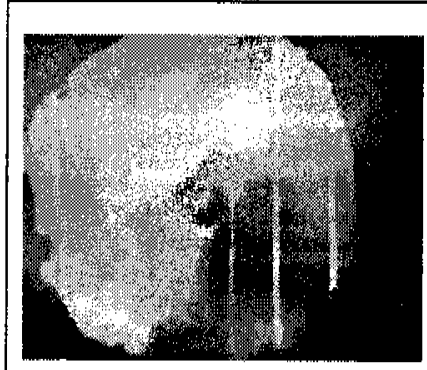

(a) Diffusion Flame

(Fucl: Satural Gas)

(Furnace termp, $=1.533 \mathrm{~K}$ )

(Preheated air temp. $=1,403 \mathrm{~K}$ )

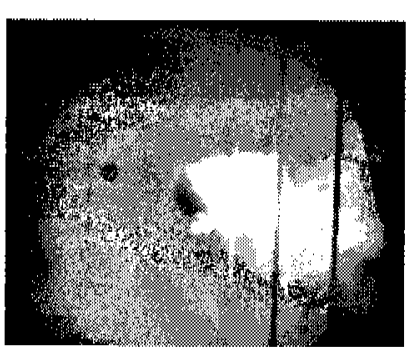

(b) Premix Flame

(Fuel : Natural Gas)

(Furnace temp. $=1,533 \mathrm{~K}$ )

(Prehcated air temp. $=1,403 \mathrm{~K}$ )
Fig. 5 Pholographs of the diffusion (lef) and premix (right).

3.2. Monochromatic profiles of the continuum (gray body) emission of radiation from soot particles

Figures 6 and 7 show the spectral intensity profiles of continuum radiation from soot particles for the premix and
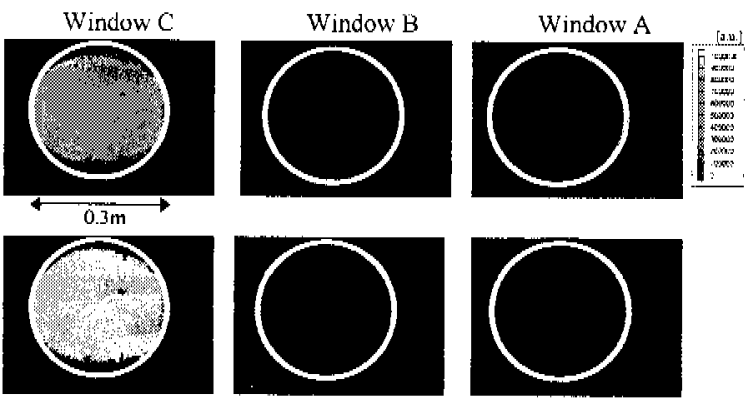

Top: $\lambda=450 \mathrm{~nm}$

Bottom: $\lambda=530 \mathrm{~nm}$
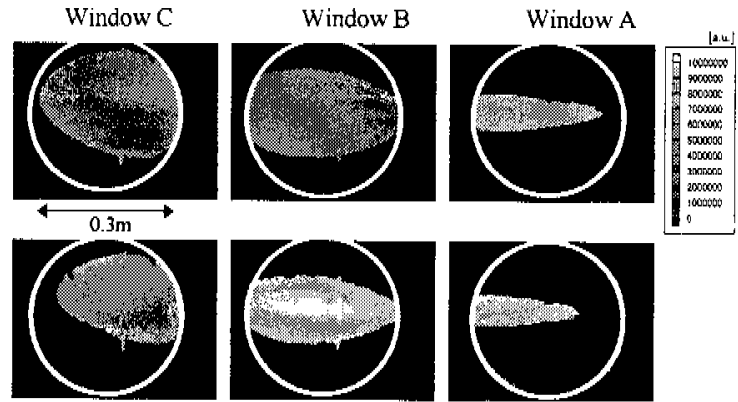

Top: $\lambda=450 \mathrm{~nm}$

Bottom: $\lambda=530 \mathrm{~nm}$

Figs.6\&7Soot radiation profiles(upper:diffusion\&lower:premix). diffusion flames, respectively. The upper and lower figures demonstrate the intensity profiles measured at the two 
wavelengths of 450 and $530 \mathrm{~nm}$, respectively.

The left, middle and right figures are the profiles observed through the windows, A, B and C, respectively. The background emission is subtracted two-dimensionally for all the profiles. It is clearly seen from those figures that the continuum emission is stronger in the downstream region at the window $\mathrm{C}$ for the diffusion flame. In the regions at the windows $A$ and $B$, the intensity is much lower and of different order levels (see profiles on the different scale in Fig. 8: note the background emission is not subtracted and the lower and rightmost figure shows almost the background emission from the furnace wall). For the premix flame, on the other hand, the continuum emission is most intensive in the middle upstream region at the window B. Figure 9 shows the detailed graduation: again note the difference in the scale. The higher emission level is seen along the central flame axis.

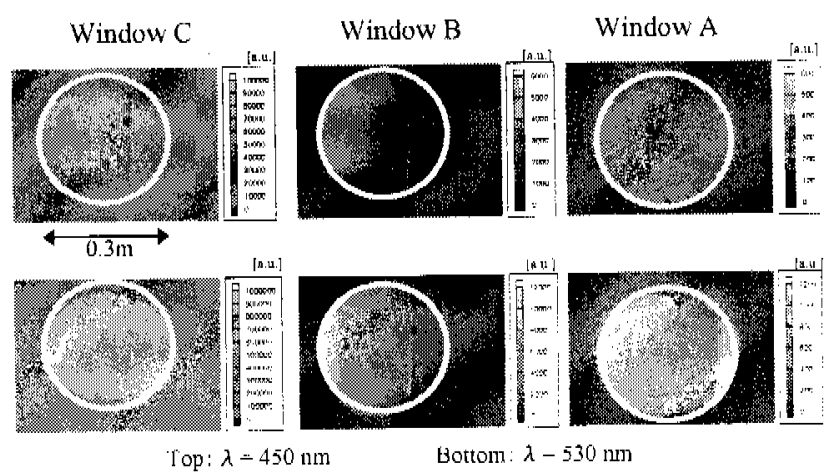

Window C Window B Window $A$
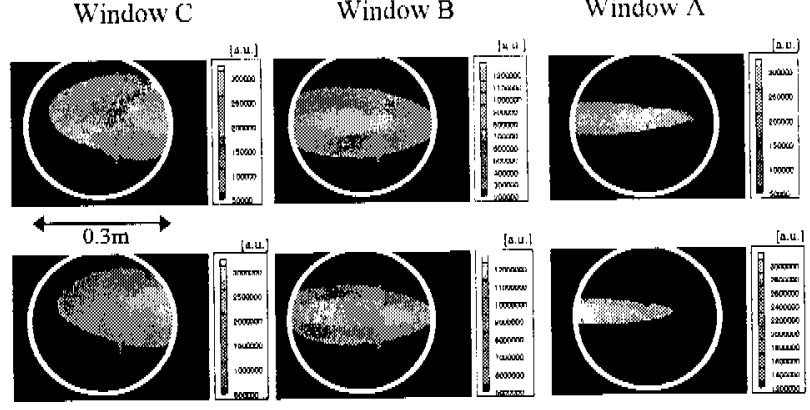

Top: $\lambda=450 \mathrm{~nm}$

Bottom: $\lambda-530 \mathrm{~nm}$

Figs. 8\&9 Profiles of Fig. $6 \& 7$ on different scales.

3.3. Two-dimensional distributions of thermocouple and spectroscopic temperatures

Figure 10 shows the temperature profiles of the diffusion flame, measured with thermocouples and by the narrow band two-dimensional two-color thermometry, and Fig. 11 those of the premix flame. The spectroscopic temperature distribution in the diffusion flame was not obtainable in the upstream region at the window $A$, because the emission intensity level is very low as described above. It is clearly seen that the two-dimensional resolution of the spectroscopic temperature is higher than that of the thermocouples temperature. During the premix combustion, the higher temperatures exist along the central flame axis and in the middle stream at the window $B$. In addition, the high temperature region is thinner compared with that during the diffusion combustion and the maximum temperature is higher in the premix flame than that in the diffusion flame (compare the profiles at the window $\mathrm{C}$ ).

Figs. 10\&11 Profiles of spectroscopic and thermocouples temperatures (upper:diffusion \& lower premix).
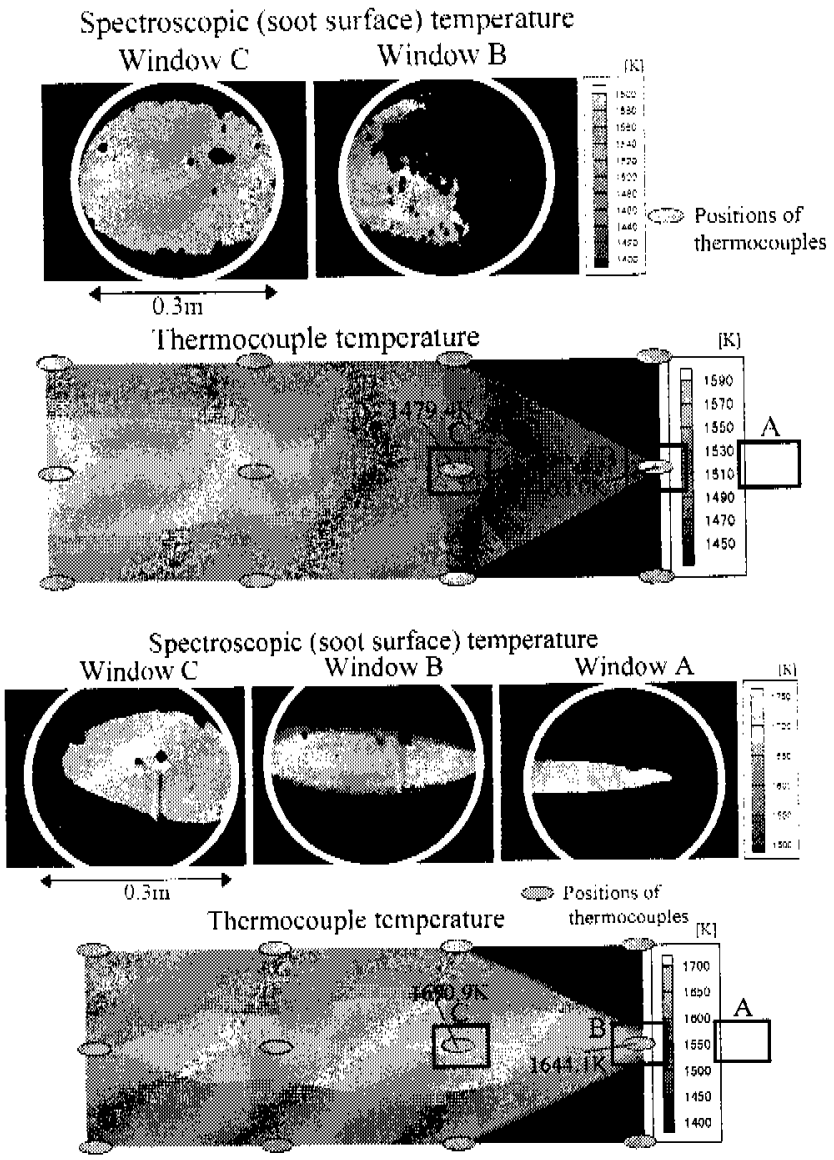

3.3. Two-dimensional distribution of spontaneous emission of radiation from $\mathrm{NO}$ molecules

Figures 12 and 13 show the intensity profiles of spontaneous emission of radiation form NO molecules in the premix and diffusion flames. Note that the different scales are used in Fig. 13, to illustrate the detailed profiles at the low level of emission intensity. It is seen that the intensity level is much lower for the diffusion flame than that for the premix flame.

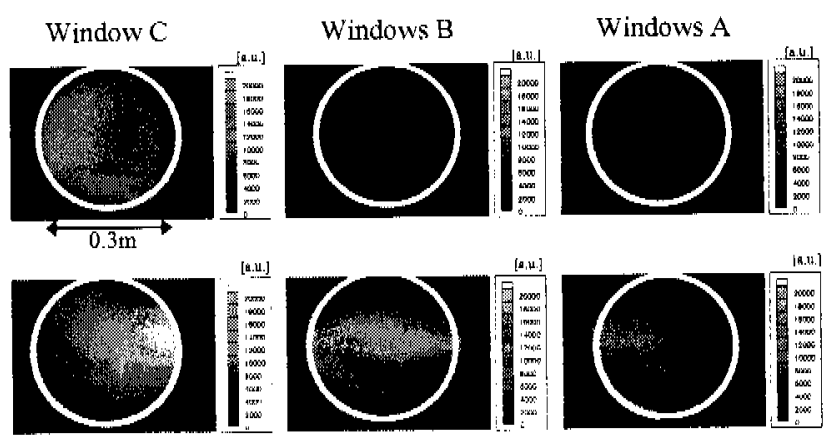

Top:Diffusion Hame Bothom: Premix flame

Fig. 12 Profiles of emission of $\mathrm{NO}$ radiation. 


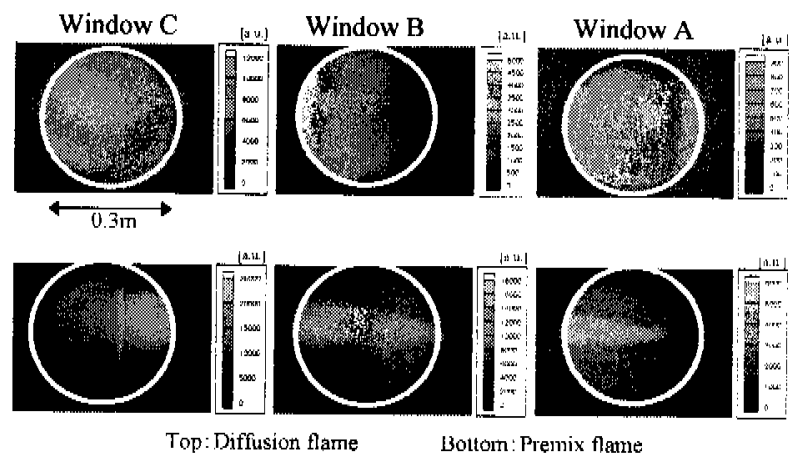

Fig. 13 Profiles of Fig. 12 on different scales.

\section{Discussion}

The NOx concentrations in the exhaust gas were 39 and $141 \mathrm{ppm}$, in terms of the concentration converted at $11 \%$ of oxygen, during the premix and diffusion combustion. Thus, the NOx emission level is ca. 3 times lower or less during the diffusion combustion. The reason for this is discussed in conjunction with the results described above.

During the premixed combustion, the flame volume is smaller and the high temperature region is confined within a narrower region along the central flame axis. This is mainly due to the faster combustion velocity. As a result, the maximum temperature also becomes higher. On the other hand, the combustion velocity becomes lower during the diffusion combustion because it takes a longer period for mixing the fuels and air. This is reflected also by the fact that the combustion does not exist in the upstream region at the window $A$. Thus, the flame volume becomes lar ger and consequently the highest temperature becomes lower.

The higher maximum temperature and the confined high temperature region is preferred by the generation of thermal NOx. This is clearly exemplified by the higher levels of intensity of spontaneous emission of radiation form NO molecules in the premix flame.

\section{Conclusions}

The followings are concluded.

(1) The test furnace of an industrial size with regenerator burners oriented to steel processing was constructed for combustion of natural gas with highly preheated air at a low concentration of oxygen.

(2) The two-dimensional measurements using the CCD camera fitted with an optical filter (spectrocamera) was successfully applied to the diagnostics of flames.

(3) The diffusion flame is preferable from a viewpoint of low NOx emission. And the source is clearly demonstrated with spectroscopic two-dimensional measurements : the high temperature distribution is confined in a narrow region of the premixed flame and consequently the maximum temperature become higher, leading to the generation of larger amounts of thermal NOx.

\section{Acknowledgement}

This work has been supported by the New Energy
Technology Development Organization (NEDO) under the contract of Higher Thermal Efficiency New Industrial Furnaces.

\section{REFERENCES}

1) Organization (NEDO), NEDO Project Reports :High Performance Industrial Furnace Development Project -High Temperature Air Combustion, March (2000).

2) NKK Corporation, NKK Technical Review No.80, July (1999) New Energy and Industrial Technology Development.

3) T.Ishiguro, S.Tsuge, T.Furuhata, K.Kitagawa, N.Arai, T.Hasegawa, R.Tanaka and A.K.Guputa: Twenty-Seventh Symp. (Int.) on Combust., The combustion Institute, Pittsburgh, USA, (1998), 3205.

4) C.L.Tien:Advances in Heat Trans., 5(1968), 253.

5) W.Heitler: The Quantum Theory of Radiation, Oxford University Press, Oxford and New York, (1954).

6) A.F.Sarofim and H.C.Hottel: Proc.of the Sixth Int. Heat Transfer Conf., Vol.6, Elsevier, Amsterdam, (1978), 199.

7) T.Ishii, C.Zhang and S.Sugiyama: Proc. of the Int. Joint Power Generation Conf., The American Society of Mechanical Engineer, New York, USA, (1997), 267.

8) C.Zhang, T.Ishii, Y.Hino, S.Sugiyama: J. of Heat Trans., 122(2000), 287 